\title{
Technical Note: Comparison between a direct and the standard, indirect method for dissolved organic nitrogen determination in freshwater environments with high dissolved inorganic nitrogen concentrations
}

\author{
D. Graeber ${ }^{1}$, J. Gelbrecht ${ }^{2}$, B. Kronvang ${ }^{1}$, B. Gücker ${ }^{3}$, M. T. Pusch ${ }^{2}$, and E. Zwirnmann ${ }^{2}$ \\ ${ }^{1}$ Department of Bioscience, Aarhus University, Vejlsøvej 25, 8600 Silkeborg, Denmark \\ ${ }^{2}$ Leibniz-Institute of Freshwater Ecology and Inland Fisheries, Müggelseedamm 301, 12587 Berlin, Germany \\ ${ }^{3}$ Federal University of São João del-Rei, Campus Dom Bosco, 36301-160 São João del-Rei, Brazil \\ Correspondence to: D. Graeber(dgr@dmu.dk)
}

Received: 6 May 2012 - Published in Biogeosciences Discuss.: 14 June 2012

Revised: 22 October 2012 - Accepted: 8 November 2012 - Published: 28 November 2012

\begin{abstract}
Research on dissolved organic nitrogen (DON) in aquatic systems with high dissolved inorganic nitrogen (DIN, the sum of $\mathrm{NO}_{3}^{-}, \mathrm{NO}_{2}^{-}$and $\mathrm{NH}_{4}^{+}$) concentrations is often hampered by high uncertainties regarding the determined DON concentration. The reason is that DON is determined indirectly as the difference between total dissolved nitrogen (TDN) and DIN. In this standard approach to determine DON concentrations, even small relative measurement errors of the DIN and TDN concentrations propagate into high absolute errors of DON concentrations at high DIN : TDN ratios. To improve the DON measurement accuracy at high DIN : TDN ratios, we investigated the DON measurement accuracy of this standard approach according to the DIN : TDN ratio and compared it to the direct measurement of DON by sizeexclusion chromatography (SEC) for freshwater systems. For this, we used standard compounds and natural samples with and without DIN enrichment. We show that for the standard approach, large errors of the determined DON concentrations at DIN : TDN ratios $>0.6$ occur for both standard compounds and natural samples. In contrast, measurements of DON by SEC always gave low errors at high DIN : TDN ratios due to the successful separation of DON from DIN. For SEC, DON recovery rates were $91-108 \%$ for five pure standard compounds and 89-103\% for two standard compounds, enriched with DIN. Moreover, SEC resulted in 93-108\% recovery rates for DON concentrations of natural samples at a DIN : TDN ratio of 0.8 and the technique was successfully applied to a range of samples from waste water treatment
\end{abstract}

plants to forest and agricultural streams. With $2.5 \mathrm{~h}$ of measurement time per sample, SEC is slower, but more accurate than the standard approach for determination of DON concentrations in freshwaters with DIN : TDN ratios $>0.6$. To sum up, the direct DON measurement by SEC enables better understanding of the nitrogen cycle of urban and agricultural freshwater systems.

\section{Introduction}

Dissolved organic nitrogen (DON) constitutes an important pool of nitrogen in freshwater (Jørgensen, 2009) and marine ecosystems (Berman and Bronk, 2003). DON may also play an important role in agricultural catchment nitrogen fluxes. For example, the mean agricultural soil leachate DON export reported in 16 studies was $12.7 \mathrm{~kg} \mathrm{ha}^{-1} \mathrm{yr}^{-1}$ and made up $26 \%$ of the total dissolved nitrogen (TDN) export (van Kessel et al., 2009). However, research on DON in agricultural and otherwise anthropogenically influenced systems is often hampered by high concentrations of dissolved inorganic nitrogen (DIN, the sum of $\mathrm{NO}_{3}^{-}, \mathrm{NO}_{2}^{-}$and $\mathrm{NH}_{4}^{+}$) which often result in high DIN : TDN ratios and low measurement accuracy for DON (e.g., Lee and Westerhoff, 2005).

The reason for this reduced measurement accuracy is that TDN, $\mathrm{NO}_{3}^{-}+\mathrm{NO}_{2}^{-}$, and $\mathrm{NH}_{4}^{+}$must be measured to calculate 
DON as DON $=\mathrm{TDN}-\left(\mathrm{NO}_{3}^{-}+\mathrm{NO}_{2}^{-}\right)-\mathrm{NH}_{4}^{+}$. In this standard approach, the subtraction of multiple independent measurements propagates the analytical variance of the single measurements into the finally determined DON concentration and at a high DIN : TDN ratio, small errors in TDN or DIN measurements can result in a large error of the calculated DON concentration (Lee and Westerhoff, 2005). Such large errors at high DIN : TDN ratios have been found for DON concentrations determined for samples from forest soils (Vandenbruwane et al., 2007) and canal water (Lee and Westerhoff, 2005). Further errors may be a result of systematic under- or overestimation in single measurements needed to calculate the DON concentration. For example, a systematic underestimation of TDN concentrations may result from incomplete conversion of the different nitrogen forms into the measured form (e.g. $\mathrm{NO}_{\mathrm{x}}$ gas in high-temperature catalytic oxidation, Bronk et al., 2000). Also, when using the Kjeldahl technique for TDN determination, underestimations of $90 \%$ have been found for DON at DIN : TDN ratios of 0.9 (Schlueter, 1977). Moreover, systematic errors of up to 2 and $4 \%$ have been reported for standard spectrophotometric measurements of $\mathrm{NO}_{3}^{-}+\mathrm{NO}_{2}^{-}$(Rutkoviene et al., 2005) and $\mathrm{NH}_{4}^{+}$(Verdouw et al., 1978), respectively. Under- or overestimations of these single measurements can even lead to the determination of negative DON concentrations as in two studies of agricultural and forest soils, in which $15 \%$ and $13 \%$ of the determined DON concentrations were found to be negative, respectively (Siemens and Kaupenjohann, 2002; Solinger et al., 2001). But even if determined DON concentrations are positive, they might be prone to under- or overestimations whose detection requires a large effort due to the different potential measurement errors of the independent measurements.

A possibility to reduce DON determination errors would be removal of DIN prior to analysis or direct measurement of DON concentrations. Removal of DIN reduces the errors propagated into DON concentrations because the error of the DON concentration should only or, if some DIN is left, almost only depend on the error of the TDN measurement (Crumpton et al., 1992; Lee and Westerhoff, 2005). Moreover, the direct measurement of DON would also result in reduced errors, as the propagation of errors associated with TDN and DIN measurements is avoided. However, until now, no direct method for DON quantification exists (Worsfold et al., 2008).

Two approaches to remove DIN prior to indirect DON measurements have been proposed in the literature: anion exchange and dialysis pretreatment. Anion exchange pretreatments were used to remove $\mathrm{NO}_{3}^{-}$and $\mathrm{NO}_{2}^{-}$from standard compounds in order to increase DON measurement accuracy (Crumpton et al., 1992; Schlueter, 1977). However, this method cannot be applied for removal of $\mathrm{NH}_{4}^{+}$(Crumpton et al., 1992; Schlueter, 1977). Dialysis pretreatment has been shown to be a simple and inexpensive method to reduce DIN concentrations in order to reliably augment the measurement accuracy of DON (Lee and Westerhoff, 2005) and different variants of this method have been applied successfully to samples from forest sites (Vandenbruwane et al., 2007) and several surface water sites (Lee and Westerhoff, 2005). However, the dialysis pretreatment is time-consuming, as DIN removal takes 24-48 h minimum (Lee and Westerhoff, 2005; Vandenbruwane et al., 2007). Another disadvantage of the dialysis pretreatment is the potential loss of part of the DON during dialysis (Lee and Westerhoff, 2005). Potential loss mechanisms are adsorption to the dialysis membrane, loss of small molecules that can permeate through the pores of the dialysis membrane (Lee and Westerhoff, 2005) and uptake of bioavailable molecules by bacteria (Vandenbruwane et al., 2007). Moreover, both anion exchange and dialysis pretreatment still rely on the subsequent indirect determination of DON by the standard approach, as often DIN is not completely removed from the sample and $\mathrm{NH}_{4}^{+}$is principally not removed by anion exchange pretreatment.

A potential direct method to measure DON could be sizeexclusion chromatography (SEC). SEC separates molecules by molecular size and polarity (Huber et al., 2011b). This separation should allow direct measurement of DON at high $\mathrm{NO}_{3}^{-}, \mathrm{NO}_{2}^{-}$and $\mathrm{NH}_{4}^{+}$concentrations, as $\mathrm{NO}_{3}^{-}, \mathrm{NO}_{2}^{-}$and $\mathrm{NH}_{4}^{+}$are separated from DON by their smaller molecular size (Huber et al., 2011b). Hence, this method would overcome the aforementioned problems of indirect DON determination at high DIN : TDN ratios. Moreover, SEC could be superior to the anion exchange pretreatment, which cannot remove $\mathrm{NH}_{4}^{+}$from a sample and should be faster than the dialysis pretreatment, as one sample can be measured within $2.5 \mathrm{~h}$ (Huber et al., 2011b). However, it has not yet been tested whether SEC efficiently separates DON and DIN by molecular size and thus can be used to directly measure DON. Moreover, SEC utilizes a UV reactor to oxidize all nitrogen to $\mathrm{NO}_{3}^{-}$, which is then measured by a UV detector (Huber et al., 2011b). The oxidation efficiency of the UV reactor and accuracy of the UV detector used in SEC systems have to be tested thoroughly for various DON standard compounds and natural substances, because UV oxidation methods may result in low DON recovery rates (Bronk et al., 2000) and the accuracy of the UV detector has previously only been tested for pure standard compounds (Huber et al., 2011b).

The aim of this study is to exemplify errors of DON measurements using the standard approach and to compare these to the novel, direct DON measurement by SEC. We used both standard DON compounds and natural samples from surface freshwaters for the comparison. 


\section{Materials and methods}

\subsection{Measurements of total dissolved nitrogen, $\mathrm{NO}_{3}^{-}+\mathrm{NO}_{2}^{-}$and $\mathrm{NH}_{4}^{+}$for the standard approach}

We measured the concentrations of TDN (determination limit $=0.1 \mathrm{mg} \mathrm{N} \mathrm{L}^{-1}$ ) using High Temperature Catalytic Oxidation (HTCO, multi N/C 3100, Jena Analytik, Germany) after acidifying the sample to $\mathrm{pH} \mathrm{2-3}$ with $\mathrm{HCl}$ and sparging for $5 \mathrm{~min}$ with synthetic air. Acidification and sparging was done to measure dissolved organic carbon concentrations, which are not reported in this study. Samples were oxidized with a platinum or special catalyst (Jena Analytik, Germany) at $700^{\circ} \mathrm{C}$ in a synthetic air stream, and TDN was measured as $\mathrm{NO}_{\mathrm{x}}$ gas with a chemiluminescence detector. These measurements are hereafter referred to as HTCO-TDN measurements. $\mathrm{NO}_{3}^{-}+\mathrm{NO}_{2}^{-}$(determination limit $=0.01 \mathrm{mg} \mathrm{N} \mathrm{L}^{-1}$ ) and $\mathrm{NH}_{4}^{+}$(determination limit $=0.03 \mathrm{mg} \mathrm{N} \mathrm{L}^{-1}$ ) were measured using standard spectrophotometric methods (ISO 13395 for $\mathrm{NO}_{3}^{-}+\mathrm{NO}_{2}^{-}$and ISO 11732 for $\mathrm{NH}_{4}^{+}$) with a SAN++ continuous flow analyzer (Skalar Analytical B.V., Breda, The Netherlands).

For total dissolved nitrogen analysis, we performed direct blank measurements of MilliQ water during the experiment. We found a mean blank concentration of $0.048 \mathrm{mg} \mathrm{N} \mathrm{L}^{-1}$ $( \pm 0.0301 \mathrm{SD}, n=8)$. Moreover, we used three different concentrations of nitrate and ammonium $(0.5,4$ and $8 \mathrm{mg} \mathrm{N} \mathrm{L}^{-1}$ ) to calculate the blank indirectly as the intercept with the $y$-axis and found a blank concentration of 0.087 and $0.055 \mathrm{mg} \mathrm{N} \mathrm{L}^{-1}$ for nitrate and ammonium, respectively.

For $\mathrm{NO}_{3}^{-}$and $\mathrm{NH}_{4}^{+}$, the $\mathrm{SAN}++$ continuous flow analyzer performs a blank measurement of MilliQ water for every ten samples after a wash sample. This blank measurement is then automatically subtracted from the next ten measurements and not reported by the instrument.

\subsection{Size-exclusion chromatography}

For size-exclusion chromatography (SEC), we used the Liquid Chromatography-Organic Carbon-Organic Nitrogen Detection system (determination limit $=0.05 \mathrm{mg} \mathrm{N} \mathrm{L}^{-1}$ ), manufactured by DOC-Labor Dr. Huber (Karlsruhe, Germany, http://www.doc-labor.de/). The system is driven by an HPLC pump (S-100, Knauer, Berlin) and consists of an autosampler (MLE, Dresden, Germany) and a chromatographic column $(250 \mathrm{~mm} \times 20 \mathrm{~mm}$, TSK HW 50S, Toso, Japan).

In SEC, a part of each sample is measured after bypassing the chromatographic column and another part after passing through the chromatographic column. Both parts are measured first by a UV detector ( $254 \mathrm{~nm}, \mathrm{~S}-200$, Knauer, Berlin, Germany) and subsequently, flow is further divided into two streams. One stream goes to a UV reactor to measure nitrogen. The UV reactor is a helical silica capillary of $4 \mathrm{~m}$ length and $1 \mathrm{~mm}$ inner diameter, fused into the electric discharge arc of a low-pressure mercury lamp (emitting at 185 and $254 \mathrm{~nm}$,
DOC-Labor, Karlsruhe). In this reactor, nitrogen is oxidized to $\mathrm{NO}_{3}^{-}$, which is then measured with an in-line UV-detector at $220 \mathrm{~nm}$ (K-2001, Knauer, Berlin, Germany). The second stream goes to a thin-film reactor where DOC is oxidized to $\mathrm{CO}_{2}$ and then to an infrared $\mathrm{CO}_{2}$ detector (Huber and Frimmel, 1991, for details on this part of the SEC system see ). The mobile phase used was a phosphate buffer of $\mathrm{pH}$ of $6.85\left(2.5 \mathrm{~g} \mathrm{KH}_{2} \mathrm{PO}_{4}+1.5 \mathrm{~g} \mathrm{Na}_{2} \mathrm{HPO}_{4} \times 2 \mathrm{H}_{2} \mathrm{O}\right.$ to $1 \mathrm{~L}$, Fluka, \#30407 and \#30412). See Huber et al. (2011b) for further details on the system.

In the weak cation-exchange chromatographic column of the SEC, molecules are separated by molecular size and polarity (Huber et al., 2011b). The column has a separation range of 0.1 to $10 \mathrm{kDa}$, resulting in fast elution of hydrophilic high-molecular weight substances of $10 \mathrm{kDa}$ or higher. This fraction is followed by a fraction similar to extracted humic and fulvic acids. Subsequently, low-molecular weight acids are eluted as a compressed peak ahead of $\mathrm{NO}_{3}^{-}$and $\mathrm{NH}_{4}^{+}$. $\mathrm{NO}_{3}^{-}$itself is separated from $\mathrm{NH}_{4}^{+}$by its polarity. The part of the nitrogen eluting before $\mathrm{NO}_{3}^{-}$or $\mathrm{NH}_{4}^{+}$will hereafter be referred to as SEC-DON.

For natural water samples, the nitrogen concentration measured in the chromatographic column bypass can exceed that of the part of each sample passing through the chromatographic column. The difference is organic matter remaining in the column (Huber et al., 2011b). In our study, the amount of nitrogen remaining in the SEC column was low for standard compounds and their recovery rates were accordingly high (Tables 2,3). For the analysed natural samples and natural organic matter (NOM) treatments (see section 2.4.2 for details on the samples), the total nitrogen measured after SEC column passage was compared to the total nitrogen measured after bypassing the SEC column. Recovery rates of 84-114\% were found in this comparison (data not shown).

During the experiment, we performed blank measurements with MilliQ water $(n=5)$. For these, we found only baseline noise but no measurable nitrogen peak. Chromatograms for these blank measurements are reported in the manuscript supplement. The mean SD of the noise for the blanks was 0.03 arbitrary units, with a minimum of 0.021 and a maximum of 0.05 . Expressed as a concentration, this SD was $0.0009 \mathrm{mg} \mathrm{NL}^{-1}$, with a minimum of $0.0006 \mathrm{mg} \mathrm{N} \mathrm{L}^{-1}$ and a maximum of $0.001 \mathrm{mg} \mathrm{N} \mathrm{L}^{-1}$. Therefore, using the mean $\mathrm{SD}$ of the noise, the blank value equalled $0.9 \mu \mathrm{g} \mathrm{N}^{-1}$ and the determination limit was $2.7 \mu \mathrm{g} \mathrm{N} \mathrm{L}-1$ $\left(0.0027 \mathrm{mg} \mathrm{NL}^{-1}\right.$; calculated as three times the mean SD of the blank measurement noise). This determination limit is higher than for urea for the same instrument reported by Huber et al. (2011b), who found a determination limit of $1 \mu \mathrm{g} \mathrm{N}^{-1}$. Thus, SEC can be considered a highly sensitive method for determination of DON in freshwaters. In this study, we assumed a detection limit of $0.05 \mathrm{mg} \mathrm{N} \mathrm{L}^{-1}$ for SEC to ensure that the samples have a sufficiently high signal:noise ratio to be measured with high accuracy. 


\subsection{Calculation of errors and statistics}

In order to calculate the random error of the determined DON concentration, we conducted Monte-Carlo (MC) simulations with 100000 realizations with the mc2d package (version 0.1-9, Pouillot and Delignette-Muller, 2010) in R (version 2.14.2, R Development Core Team, 2012). For the MC simulations, normal distribution of the input variables was assumed. Depending on the experiment, the input variables were $\mathrm{HTCO}-\mathrm{TDN}, \mathrm{NO}_{3}^{-}$and/or $\mathrm{NH}_{4}^{+}$and hence in the $\mathrm{MC}$ simulations, DON was calculated as DON $=\mathrm{HTCO}-\mathrm{TDN}-\left(\mathrm{NO}_{3}^{-}+\mathrm{NO}_{2}^{-}\right)-\mathrm{NH}_{4}^{+}$, as $\mathrm{DON}=\mathrm{HTCO}-\mathrm{TDN}-\left(\mathrm{NO}_{3}^{-}+\mathrm{NO}_{2}^{-}\right)$or as $\mathrm{DON}=\mathrm{HTCO}-$ $\mathrm{TDN}-\mathrm{NH}_{4}^{+}$. To investigate the source of the uncertainty of DON measurements, we used a sensitivity analysis (tornado function, mc2d package in R), which is a Pearson correlation between the variability of each of the input variables and the variability of the calculated DON concentration, whereby the variability of all other input variables is kept stable (Pouillot and Delignette-Muller, 2010).

Recovery rates were calculated as recovery rate $(\%)=100 \times$ measured concentration : true concentration. This calculation was made for various standard compounds with known DON concentrations and also for the natural samples for which the concentration could be measured with high accuracy (see Samples and treatments for details).

To test for significant differences between MC simulation results or to compare $\mathrm{MC}$ simulation results with directly measured SEC-DON concentrations, a pairwise, two-sided, exact bootstrap test with 9999 bootstrap resamples (Efron and Tibshirani, 1993) was conducted in $\mathrm{R}(\alpha=0.05$, see detailed description in Appendix A). The reason for choosing this test was that MC simulations with 100000 iterations deliver 100000 simulated cases to test. However, the number of real measurement replicates for the input variables of the MC simulation (HTCO-TDN, DIN) was much smaller, depending on the experiment (5-11 replicates in our case). Hence, the bootstrap test was needed to test for significant differences between different treatments to obtain a realistic number of measurement replicates (we used $n=5$ or 6 ). To control for the $\alpha$ error in multiple pairwise comparisons, we used a Sequential Bonferroni correction (Quinn and Keough, 2002).

\subsection{Samples and treatments}

All natural samples used in the assessment were filtered through a $0.45 \mu \mathrm{m}$ filter with $8 \mu \mathrm{m}$ pre-filter prior to the measurements (cellulose-acetate membrane filters, Sartorius, Göttingen). Filters were rinsed with 1 L DI water and $300 \mathrm{~mL}$ sample water before sample filtration. This intensive rinsing was conducted to ensure that no filter impurities affected the measurements.

To allow comparison of the experimental results, the same samples and standard compounds were used in different ex- periments and treatments. To provide a better overview, we have summed up all samples and treatments in a table (Table 1). For some samples, $\mathrm{NO}_{3}^{-}$and/or $\mathrm{NH}_{4}^{+}$were added to increase the DIN : TDN ratio (Table 1) and the resulting dilution was included in the calculation of recovery rates and concentrations.

\subsubsection{Errors of the standard approach}

To assess the reliability of the standard approach in dependence of the DIN : TDN ratio of natural samples, we conducted a screening of 99 streams and rivers draining agricultural, forested and wetland catchments in northeast Germany (please see the Supplement for a map, coordinates and nitrogen concentrations of the screening sites). For each of the screening samples, HTCO-TDN was measured with three measurement replicates, and $\mathrm{NO}_{3}^{-}+\mathrm{NO}_{2}^{-}$as well as $\mathrm{NH}_{4}^{+}$ were measured with two measurement replicates (row 1 in Table 1).

To test the recovery rates of the DON concentrations determined by the standard approach in dependence of the DIN : TDN ratio, we used two standard compounds and one natural sample from a wetland outflow $\left(52^{\circ} 20.73^{\prime} \mathrm{N}\right.$, $14^{\circ} 11.81^{\prime}$ E, rows $2-4$ in Table 1 ): L-tyrosine (100\% purity, Sigma Chemical CO, St. Louis, USA) and imidazole (>99\% purity, Merck, Darmstadt, Germany). Both standard compounds were enriched with $\mathrm{NO}_{3}^{-}$(CertiPUR, Merck, Darmstadt, Germany) to reach DIN : TDN ratio levels of 0.2, 0.4, $0.5,0.6,0.7$ and 0.8 . In contrast, the wetland outflow was characterized by a high $\mathrm{NH}_{4}^{+}$concentration $\left(0.6 \mathrm{mg} \mathrm{N}^{-1}\right)$ compared to the TDN concentration $\left(1.5 \mathrm{mg} \mathrm{NL}^{-1}\right)$; therefore, the $\mathrm{NO}_{3}^{-}$enrichment started with a DIN : TDN ratio of 0.4 . Samples were enriched to DIN : TDN ratios of 0.5, 0.6, 0.7, 0.8 and 0.9. At all levels of enrichment, the TDN concentration was $2 \mathrm{mg} \mathrm{N} \mathrm{L}^{-1}$ for the standard compounds and $1.5 \mathrm{mg} \mathrm{N} \mathrm{L}^{-1}$ for the natural sample. At each level of enrichment, $\mathrm{NO}_{3}^{-}+\mathrm{NO}_{2}^{-}$and HTCO-TDN were measured for the standard compounds, and $\mathrm{NO}_{3}^{-}+\mathrm{NO}_{2}^{-}, \mathrm{NH}_{4}^{+}$and HTCOTDN were measured for the natural sample. Each variable was measured with six measurement replicates at each level of enrichment.

Recovery rates for the standard compounds were calculated based on the known, true concentration and the recovery rate for the sample from the wetland outflow was calculated as the percent deviation from the concentration measured at a DIN : TDN ratio of 0.4 . No recovery rates were calculated for the samples of the screening due to unknown true DON concentrations. The reason was the interference of DIN in the indirect determination of DON at the high DIN : TDN ratios of the screening samples.

We used MC simulations to calculate the random error of the determined DON concentrations, as described previously. For the samples of the screening, the input variables for the MC simulation were HTCO-TDN, $\mathrm{NH}_{4}^{+}$ and $\mathrm{NO}_{3}^{-}+\mathrm{NO}_{2}^{-}$. For the standard compounds, the input 
Table 1. Treatments, samples and number of measurement replicates used in the study. NOM = natural organic matter.

\begin{tabular}{|c|c|c|c|c|c|c|}
\hline \multirow[b]{2}{*}{ Experiment } & \multirow[b]{2}{*}{ Treatment } & \multirow[b]{2}{*}{ Sample } & \multicolumn{4}{|c|}{ Measurement replicates } \\
\hline & & & TDN & $\mathrm{NO}_{3}^{-}$ & $\mathrm{NH}_{4}^{+}$ & SEC \\
\hline \multirow{4}{*}{$\begin{array}{l}\text { Std. approach } \\
\text { vs. DIN : TDN ratio }\end{array}$} & Samples with natural concentration & 99 samples from various sites & 3 & 2 & 2 & n.m. \\
\hline & Sample enriched with $\mathrm{NO}_{3}^{-}$ & Wetland outflow & 6 & 6 & 6 & n.m. \\
\hline & Sample enriched with $\mathrm{NO}_{3}^{-}$ & L-tyrosine & 6 & 6 & n.m. & n.m. \\
\hline & Sample enriched with $\mathrm{NO}_{3}^{-}$ & Imidazole & 6 & 6 & n.m. & n.m. \\
\hline \multirow{22}{*}{$\begin{array}{l}\text { Std. approach } \\
\text { vs. SEC }\end{array}$} & Pure standard compounds & Glycine & $6 / 9 / 6^{\mathrm{a}}$ & n.m. & n.m. & $2 / 2 / 2^{\mathrm{a}}$ \\
\hline & Pure standard compounds & Imidazole & $6 / 15 / 6^{\mathrm{a}}$ & n.m. & n.m. & $2 / 6 / 2^{\mathrm{a}}$ \\
\hline & Pure standard compounds & Nicotinic acid & $6 / 8 / 6^{\mathrm{a}}$ & n.m. & n.m. & $2 / 5 / 2^{\mathrm{a}}$ \\
\hline & Pure standard compounds & L-tyrosine & $6 / 8 / 15^{\mathrm{a}}$ & n.m. & n.m. & $2 / 2 / 7^{\mathrm{a}}$ \\
\hline & Sample enriched with $\mathrm{NO}_{3}^{-}$ & Imidazole & 6 & 6 & n.m. & 2 \\
\hline & Sample enriched with $\mathrm{NO}_{3}^{-}$ & L-tyrosine & 6 & 6 & n.m. & 2 \\
\hline & NOM pure / enriched with DIN & Fuchskuhle NOM & 11 & 6 & 6 & 5 \\
\hline & NOM pure / enriched with DIN & Fuchskuhle $\mathrm{NOM}+\mathrm{NO}_{3}^{-}$ & 6 & 6 & 5 & 5 \\
\hline & NOM pure / enriched with DIN & Fuchskuhle $\mathrm{NOM}+\mathrm{NH}_{4}^{+}$ & 6 & 5 & 5 & 5 \\
\hline & NOM pure / enriched with DIN & Fuchskuhle $\mathrm{NOM}+\mathrm{NO}_{3}^{-}+\mathrm{NH}_{4}^{+}$ & 5 & 6 & 4 & 5 \\
\hline & NOM pure / enriched with DIN & Schwarzer See NOM & 6 & 6 & 6 & 5 \\
\hline & NOM pure / enriched with DIN & Schwarzer See $\mathrm{NOM}+\mathrm{NO}_{3}^{-}$ & 6 & 6 & 6 & 5 \\
\hline & NOM pure / enriched with DIN & Schwarzer See NOM + $\mathrm{NH}_{4}^{+}$ & 6 & 6 & 6 & 5 \\
\hline & NOM pure / enriched with DIN & Schwarzer See $\mathrm{NOM}+\mathrm{NO}_{3}^{-}+\mathrm{NH}_{4}^{+}$ & 6 & 6 & 6 & 5 \\
\hline & NOM pure / enriched with DIN & Wetland outflow NOM & 6 & 6 & 6 & 5 \\
\hline & NOM pure / enriched with DIN & Wetland outflow $\mathrm{NOM}+\mathrm{NO}_{3}^{-}$ & 6 & 6 & 6 & 5 \\
\hline & NOM pure / enriched with DIN & Wetland outflow $\mathrm{NOM}+\mathrm{NH}_{4}^{+}$ & 6 & 6 & 6 & 5 \\
\hline & NOM pure / enriched with DIN & Wetland outflow $\mathrm{NOM}+\mathrm{NO}_{3}^{-}+\mathrm{NH}_{4}^{+}$ & 6 & 6 & 6 & 5 \\
\hline & Sample with natural $\mathrm{N}$ concentrations & Forest stream 1 and 2 & 6 & 6 & 6 & 5 \\
\hline & Sample with natural $\mathrm{N}$ concentrations & Waste water samples 1 and 2 & 6 & 6 & 6 & 5 \\
\hline & Sample with natural $\mathrm{N}$ concentrations & GER agricultural tile drain/ agricultural stream & 6 & $6 / 5^{\mathrm{b}}$ & 6 & 5 \\
\hline & Sample with natural $\mathrm{N}$ concentrations & DK agricultural stream 1 and 2 & 6 & 6 & 6 & 5 \\
\hline
\end{tabular}

${ }^{a}$ Measurement replicates for standard compound concentrations of $0.5 / 4 / 8 \mathrm{mg} \mathrm{N} \mathrm{L}^{-1}$.

$\mathrm{b}$ Please note the different numbers of measurement replicates for the German agricultural tile drain/ stream.

variables were $\mathrm{HTCO}-\mathrm{TDN}$ and $\mathrm{NO}_{3}^{-}+\mathrm{NO}_{2}^{-}$and for the sample from the wetland outflow, the input variables were HTCO-TDN, $\mathrm{NH}_{4}^{+}$and $\mathrm{NO}_{3}^{-}+\mathrm{NO}_{2}^{-}$. For all samples, we used the sensitivity analysis described previously to investigate the source of the random error for the determined DON concentrations.

\subsubsection{Comparison of standard approach and SEC}

To compare the reliability of SEC to that of the standard approach across a range of concentrations $(0.5,4$ and $8 \mathrm{mg} \mathrm{N}^{-1}$ ), we used four standard compounds (row $5-8$ in Table 1): L-tyrosine, imidazole, nicotinic acid (>99\% Merck, Darmstadt, Germany) and glycine (>99.7\%, Merck). For these, SEC-DON as well as HTCO-TDN were measured to compare both methods. Because we used pure standard compounds, HTCO-TDN was assumed to equal DON. Three of these standard compounds were measured with more than two replicates by SEC to calculate the error of the SEC measurement for a concentration of 4 (imidazole $(n=6)$, nicotinic acid $(n=5)$ or $8 \mathrm{mg} \mathrm{N}^{-1}$ (L-tyrosine $(n=7)$, rows $6-8$ in Table 1) as coefficient of variation.
In a second step, we enriched L-tyrosine and imidazole with $\mathrm{NO}_{3}^{-}$to reach DIN : TDN ratios of 0.2, 0.4, 0.5, 0.6, 0.7 or 0.8 (rows $9-10$ in Table 1). TDN was kept stable at $2 \mathrm{mg} \mathrm{N} \mathrm{L}^{-1}$ at all levels of enrichment. SEC-DON, HTCOTDN and $\mathrm{NO}_{3}^{-}+\mathrm{NO}_{2}^{-}$were measured and DON was calculated by the standard approach from HTCO-TDN and $\mathrm{NO}_{3}^{-}+\mathrm{NO}_{2}^{-}$measurements. For each of the enrichment levels, recovery rates were calculated as the difference between true concentrations of the standard compounds and the DON determinations by SEC-DON or the standard approach, respectively.

To compare the accuracy of the results from the standard approach and SEC-DON measurements for natural samples, we used natural organic matter (NOM) extracted by reverse osmosis from Fuchskuhle $\left(53^{\circ} 6.34^{\prime} \mathrm{N}, 12^{\circ} 59.09^{\prime} \mathrm{E}\right)$ and Lake Schwarzer See $\left(52^{\circ} 58.66^{\prime} \mathrm{N}, 13^{\circ} 52.05^{\prime} \mathrm{E}\right)$, a pond and a lake with a high percentage of organic soils in their catchment (hereafter referred to as Fuchskuhle NOM and Schwarzer See NOM). As a third NOM sample, we used a sample from the same wetland outflow as described above. In contrast to the first sample used above (Sect. 2.4.1), $\mathrm{NO}_{3}^{-}+\mathrm{NO}_{2}^{-}$and $\mathrm{NH}_{4}^{+}$were below detection limits. No reverse osmosis extraction was conducted for the sample from 
the wetland outflow. We measured pure NOM from the Fuchskuhle, Schwarzer See and wetland outflow as SECDON and by the standard approach (HTCO-TDN minus DIN). Subsequently, DIN was added to adjust the samples to a DIN : TDN ratio of 0.8. (rows 11-22 in Table 1). For this either $\mathrm{NO}_{3}^{-}$or $\mathrm{NH}_{4}^{+}$or both were added, whereby the DON concentration was kept at the same level for all treatments. Subsequently, all treatments were measured again by SEC-DON and the standard approach. Moreover, we measured DON in water samples from two forest streams, two waste water outflows and three agricultural streams, as well as an agricultural tile drain by SEC-DON and the standard approach in order to compare both methods (rows 2226 in Table 1). The forest streams were situated close to Berlin in forested catchments $\left(52^{\circ} 15.51^{\prime} \mathrm{N}, 014^{\circ} 04.50^{\prime} \mathrm{E}\right.$ and $52^{\circ} 5.83^{\prime} \mathrm{N}, 014^{\circ} 29.11^{\prime} \mathrm{E}$, Spree catchment, $>70 \%$ forest), the waste water samples were taken from the outflow of waste water treatment plants Münchehofe (waste water 1, $52^{\circ} 29.23^{\prime} \mathrm{N}, 13^{\circ} 39.49^{\prime} \mathrm{E}$ ) and Waßmannsdorf (waste water $2,52^{\circ} 23.01^{\prime} \mathrm{N}, 13^{\circ} 28,08^{\prime} \mathrm{E}$ ), which treat a part of the sewage from the city of Berlin (Germany). Two of the agricultural stream samples were taken in Denmark $\left(55^{\circ} 29.15^{\prime} \mathrm{N}\right.$, $9^{\circ} 12.02^{\prime} \mathrm{E}$ and $56^{\circ} 13.65^{\prime} \mathrm{N}, 9^{\circ} 45.74^{\prime} \mathrm{E}$, hereafter referred to as DK agricultural stream 1 and 2) and the third agricultural stream sample $\left(52^{\circ} 22.09^{\prime} \mathrm{N}\right.$ and $\left.14^{\circ} 11.71^{\prime} \mathrm{E}\right)$, as well as the agricultural tile drain sample $\left(52^{\circ} 22.13^{\prime} \mathrm{N}, 14^{\circ} 11.67^{\prime} \mathrm{E}\right)$ were taken in Germany (hereafter referred to as GER agricultural stream and GER agricultural tile drain). All agricultural samples were taken in catchments with $>80 \%$ arable land.

A MC simulation, using the respective input variables (HTCO-TDN, $\mathrm{NO}_{3}^{-}+\mathrm{NO}_{2}^{-}$and/or $\mathrm{NH}_{4}^{+}$) was conducted for the NOM treatments with added $\mathrm{NO}_{3}^{-}$and/or $\mathrm{NH}_{4}^{+}$, as well as forest stream 1 and 2, waste water 1 and 2, DK agricultural stream 1 and 2, GER agricultural stream and GER agricultural tile drain to determine the uncertainty of the DON concentration calculated by the standard approach. The pairwise bootstrap test was used to test for significant differences in the DON concentration between the NOM treatments for both the standard approach and SEC-DON. This test was also used to test for significant differences between the standard approach and SEC-DON measurement within each NOM treatment. For the forest stream 1 and 2, waste water 1 and 2, DK agricultural stream 1 and 2, GER agricultural stream and GER agricultural tile drain, the same test was used to test for differences in the DON concentration determined by the standard approach or SEC-DON within the sites.

\section{Results}

\subsection{Errors of the standard approach}

In the screening of 99 sites, the mean DIN : TDN ratio of all samples was 0.75 , and above a DIN : TDN ratio of 0.8 the random error of the calculated DON concentration was often pronounced (Fig. 1). Moreover, in some samples, negative DON concentrations with DIN:TDN ratios $>1$ were measured with the standard approach (Fig. 1). The sensitivity analysis of the $\mathrm{MC}$ simulation revealed high correlation between the variability in DON and HTCO-TDN concentrations (mean $r=0.94 \pm 0.181 \mathrm{SD}, n=99$ ). In contrast, variability in DON correlated much less with that in $\mathrm{NO}_{3}^{-}+\mathrm{NO}_{2}^{-}$ (mean $r=-0.22 \pm 0.271 \mathrm{SD}, n=99$ ) or in $\mathrm{NH}_{4}^{+}$concentrations (mean $r=-0.08 \pm 0.11 \mathrm{SD}, n=99$ ).

To investigate the recovery rate of the standard approach in dependence of the DIN : TDN ratio, we used two standard compounds and one natural sample from a wetland outflow. The systematic error increased with the DIN:TDN ratio, and recovery rates deviated substantially from $100 \%$ when the DIN : TDN ratio was $>0.6-0.8$ (Fig. 2a). For the standard compounds (L-tyrosine, imidazole) DON was underestimated, and for the wetland outflow, DON was overestimated. As for the screening of 99 sites, a sensitivity analysis of the MC simulation was used to determine the source of the random error of the standard compound and the wetland outflow. It revealed a strong correlation between the variability in the calculated DON concentrations and that in the HTCO-TDN concentrations, with a minimum Pearson $r$ of 0.88 for all samples and enrichment levels (Fig. 2b). In contrast, the correlation between the variability in DON and that in $\mathrm{NO}_{3}^{-}+\mathrm{NO}_{2}^{-}$concentrations (L-tyrosine, imidazole, wetland outflow) or variability in DON and in $\mathrm{NH}_{4}^{+}$concentrations (wetland outflow) was weak (maximum of Pearson $r=-0.48$, Fig. 2b).

\subsection{Comparison of standard approach and size-exclusion chromatography}

For pure standard compounds, the range of recovery rates was $91-108 \%$ (Table 2) for SEC-DON. In contrast, the range of recovery rates was $96-124 \%$ for HTCO-TDN. The HTCO-TDN measurements especially overestimated concentrations at $0.5 \mathrm{mg} \mathrm{N} \mathrm{L}^{-1}$ and the recovery rate was not improved by using calibration curves for low concentrations only $\left(0.1-1 \mathrm{mg} \mathrm{N} \mathrm{L}^{-1}\right)$. When excluding the measurements at $0.5 \mathrm{mg} \mathrm{N} \mathrm{L}^{-1}$, we found recovery rates between 96 and $105 \%$ for HTCO-TDN. For SEC, three of these standard compounds were measured with more replicates (imidazole, nicotinic acid and L-tyrosine, rows 6-8 in Table 1 ). We found coefficients of variation (CV) of 7\%, $2 \%$ and $3 \%$ for imidazole, nicotinic acid and L-tyrosine measurements, respectively.

For the DIN-enriched standard compounds, the mean recovery rate of SEC-DON was often closer to $100 \%$ than for the standard approach (Table 3). This was always the case at DIN : TDN ratios $>0.4$.

In the SEC measurements of DIN-enriched Fuchskuhle NOM, SEC clearly separated the peaks of DON from the ones of $\mathrm{NO}_{3}^{-}$and $\mathrm{NH}_{4}^{+}$(Fig. 3). In all other measured samples, we found the same clear separation of DON and DIN, 


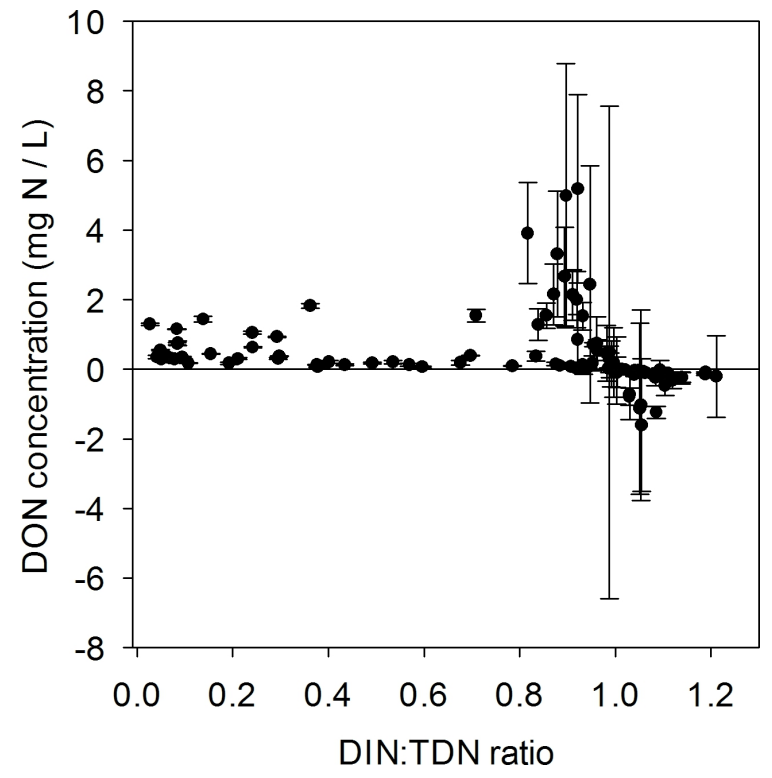

Fig. 1. Mean \pm 1 SD of DON concentrations versus the DIN : TDN ratio measured by the standard approach (HTCO-TDN minus DIN) for the screening of 99 streams and rivers draining northeastern German catchments. Means and uncertainties were determined by MC simulations for the standard approach with 3 measurement replicates for HTCO-TDN and 2 measurement replicates for $\mathrm{NO}_{3}^{-}+\mathrm{NO}_{2}^{-}$and $\mathrm{NH}_{4}^{+}$.

except for the waste water samples for which DON and DIN were not perfectly separated (please see the Supplementary material for the chromatograms). We found low measurement errors in SEC for the Fuchskuhle NOM, Schwarzer See NOM and wetland outflow with and without added DIN (Fig. 4) and these measurement errors were always similar to or less than for the standard approach (HTCO-TDN minus DIN; Fig. 4). Also, for forest stream 1 and 2, waste water 2, GER agricultural stream, GER agricultural tile drain and DK agricultural stream 1 and 2, the measurement errors, as indicated by $\mathrm{CV}$, were lower for SEC than for the standard approach (Table 4).

For the Fuchskuhle NOM without addition of DIN, concentrations of DON determined by SEC were similar to those determined by the standard approach (Fig. 4a). In contrast, for the Schwarzer See NOM and the wetland outflow without addition of DIN, the DON concentrations determined by SEC were lower $\left(0.83 \mathrm{mg} \mathrm{N} \mathrm{L}^{-1}\right.$ for Schwarzer See NOM and $1.02 \mathrm{mg} \mathrm{N} \mathrm{L}^{-1}$ for the wetland outflow) than for the standard approach (1.04 $\mathrm{mg} \mathrm{N} \mathrm{L}^{-1}$ for Schwarzer See NOM and $1.10 \mathrm{mg} \mathrm{N} \mathrm{L}^{-1}$ for the wetland outflow; Fig. $4 \mathrm{~b}, \mathrm{c}$ ). When expressed as percentages, the SEC measurement resulted in a $19 \%$ underestimation of DON for Schwarzer See NOM and a $5 \%$ underestimation of DON for the wetland outflow compared with the standard approach.
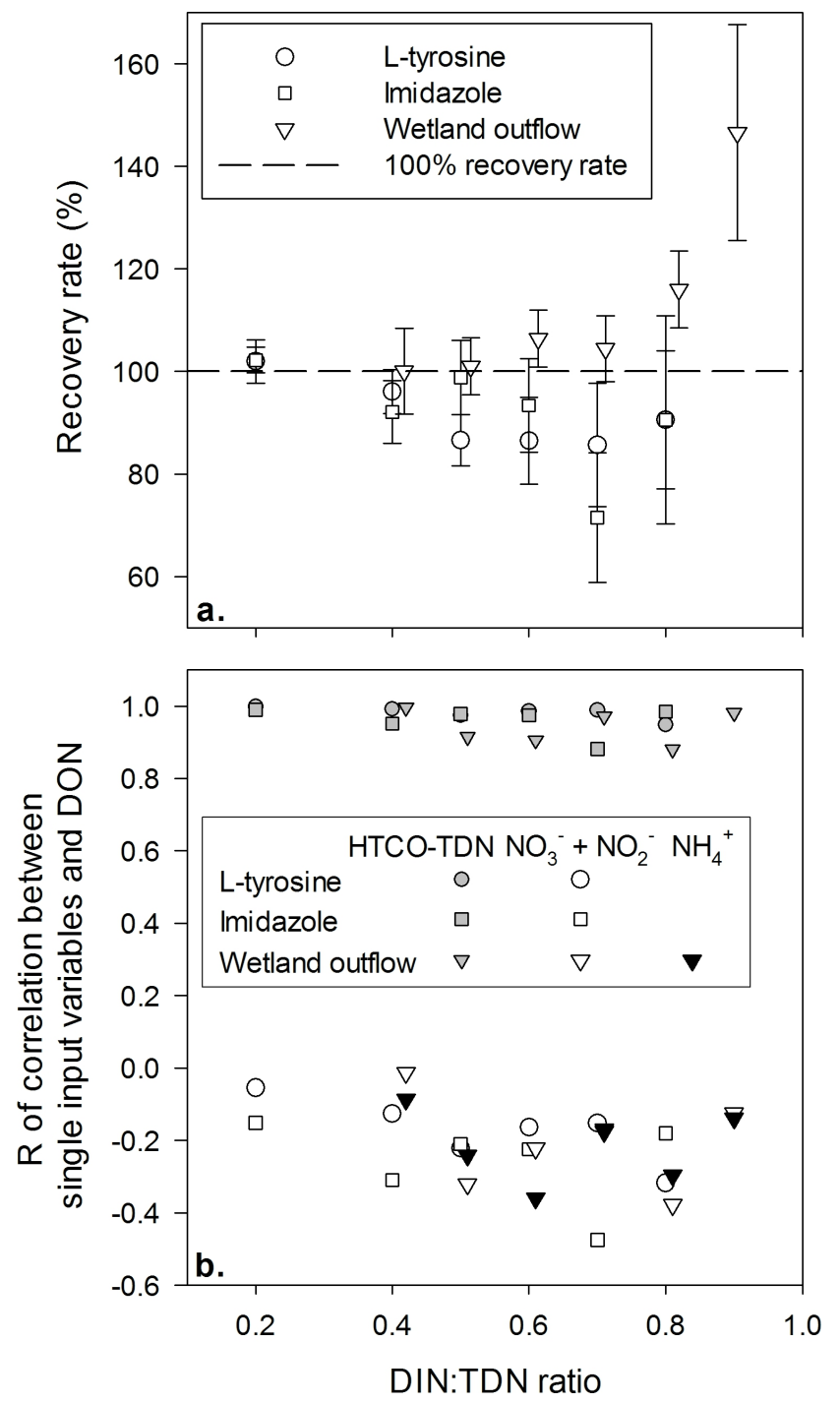

Fig. 2. Effect of $\mathrm{NO}_{3}^{-}$enrichment on the recovery rate of DON (mean $\pm 1 \mathrm{SD}$ of 6 measurement replicates) determined by MC simulations for the standard approach (a) and results from the sensitivity analysis of the MC simulations (b). Correlation coefficients ( $R=$ Pearson $r$ ) are given for correlations between the variability of the input variables and the variability of the calculated DON concentration. Please see Table 1 for further details on the samples.

For Fuchskuhle NOM, Schwarzer See NOM and the wetland outflow, the recovery rates were calculated using the sample without DIN addition as reference. With recovery rates of $-28-209 \%$, the standard approach often substantially under- or overestimated the DON concentration for the treatments when $\mathrm{NO}_{3}^{-}$and/or $\mathrm{NH}_{4}^{+}$have been added to reach DIN : TDN ratios of 0.8 . The absolute values of these underor overestimations were in most cases significantly different from the treatment without DIN addition (Fig. 4). The DON concentration determined by the standard approach was even negative for the wetland outflow with added $\mathrm{NO}_{3}^{-}$(Fig. 4). 
Table 2. Measured concentrations and recovery rates of HTCO-TDN (6-15 measurement replicates) and SEC-DON (2-7 measurement replicates) for four standard compounds at three standard concentration levels (Std. conc.). Please see Table 1 for further details on the samples.

\begin{tabular}{lrrrrrr}
\hline \multirow{2}{*}{ Std. compound } & Std. conc. & \multicolumn{2}{c}{ HTCO-TDN } & & \multicolumn{2}{c}{ SEC-DON } \\
\cline { 3 - 4 } \cline { 6 - 7 } & mg N L $^{-1}$ & $\mathrm{mg} \mathrm{N} \mathrm{L}^{-1}$ & \% Recovery & & mg N L $^{-1}$ & \% Recovery \\
\hline Glycine & 0.5 & 0.58 & 116.1 & & 0.48 & 95.6 \\
Glycine & 4.0 & 3.87 & 96.7 & & 3.75 & 93.8 \\
Glycine & 8.0 & 7.94 & 99.3 & & 8.00 & 99.9 \\
Imidazole & 0.5 & 0.53 & 105.9 & & 0.45 & 90.7 \\
Imidazole & 4.0 & 3.90 & 97.6 & & 4.13 & 103.3 \\
Imidazole & 8.0 & 7.7 & 96.4 & & 7.40 & 92.4 \\
Nicotinic acid & 0.5 & 0.58 & 117.0 & & 0.53 & 105.2 \\
Nicotinic acid & 4.0 & 4.19 & 104.8 & & 4.31 & 107.9 \\
Nicotinic acid & 8.0 & 8.29 & 103.6 & & 8.18 & 102.3 \\
L-tyrosine & 0.5 & 0.62 & 123.5 & & 0.50 & 100.4 \\
L-tyrosine & 4.0 & 3.97 & 99.1 & & 4.04 & 101.0 \\
L-tyrosine & 8.0 & 8.24 & 103.0 & & 8.36 & 104.5 \\
\hline
\end{tabular}

Table 3. Recovery rates (\%) of DON standard compounds determined by the standard approach (Std. approach: HTCO-TDN minus $\mathrm{NO}_{3}^{-}, 6$ measurement replicates) and SEC-DON measurements (2 measurement replicates) for L-tyrosine and imidazole at different DIN : TDN ratios, adjusted by the addition of $\mathrm{NO}_{3}^{-}$. Please see Table 1 for further details on the samples.

\begin{tabular}{lrrrrrr}
\hline \multirow{2}{*}{ DIN : TDN ratio } & \multicolumn{2}{c}{ Imidazole } & & \multicolumn{2}{c}{ L-tyrosine } \\
\cline { 2 - 3 } \cline { 5 - 7 } & $\begin{array}{r}\text { Std. } \\
\text { approach }\end{array}$ & SEC- & & $\begin{array}{r}\text { Std. } \\
\text { DON }\end{array}$ & & SEC- \\
approach & DON \\
\hline 0.2 & 102.2 & 94.1 & & 102.0 & 92.9 \\
0.4 & 92.1 & 99.2 & & 96.1 & 96.9 \\
0.5 & 98.8 & 100.4 & & 86.6 & 90.1 \\
0.6 & 93.4 & 99.6 & & 86.5 & 89.3 \\
0.7 & 71.5 & 102.1 & & 85.7 & 97.5 \\
0.8 & 90.6 & 102.9 & & 90.6 & 96.9 \\
\hline Mean & 91.4 & 99.7 & & 91.2 & 93.9 \\
\hline
\end{tabular}

In contrast, the recovery rates of the SEC-DON measurements amounted to 93-108\% (Fig. 4) for Fuchskuhle NOM, Schwarzer See NOM and the wetland outflow sample with added $\mathrm{NO}_{3}^{-}$and/or $\mathrm{NH}_{4}^{+}$and the determined DON concentrations were always positive (Fig. 4).

For Fuchskuhle NOM, Schwarzer See NOM and the wetland outflow, the main reason for the over- or underestimated DON concentrations by the standard approach was the false estimation of HTCO-TDN. Compared with the treatment without DIN, the recovery rates of the HTCOTDN concentrations were 123,123 and $135 \%$ for the Fuchskuhle $\mathrm{NOM}$ with added $\mathrm{NO}_{3}^{-}, \mathrm{NH}_{4}^{+}$and $\mathrm{NH}_{4}^{+}+\mathrm{NO}_{3}^{-}$, respectively. For the Schwarzer See NOM, the recovery rates were 94,101 and $97 \%$ for the addition with $\mathrm{NO}_{3}^{-}, \mathrm{NH}_{4}^{+}$and $\mathrm{NH}_{4}^{+}+\mathrm{NO}_{3}^{-}$, respectively. For the wetland outflow, the re-

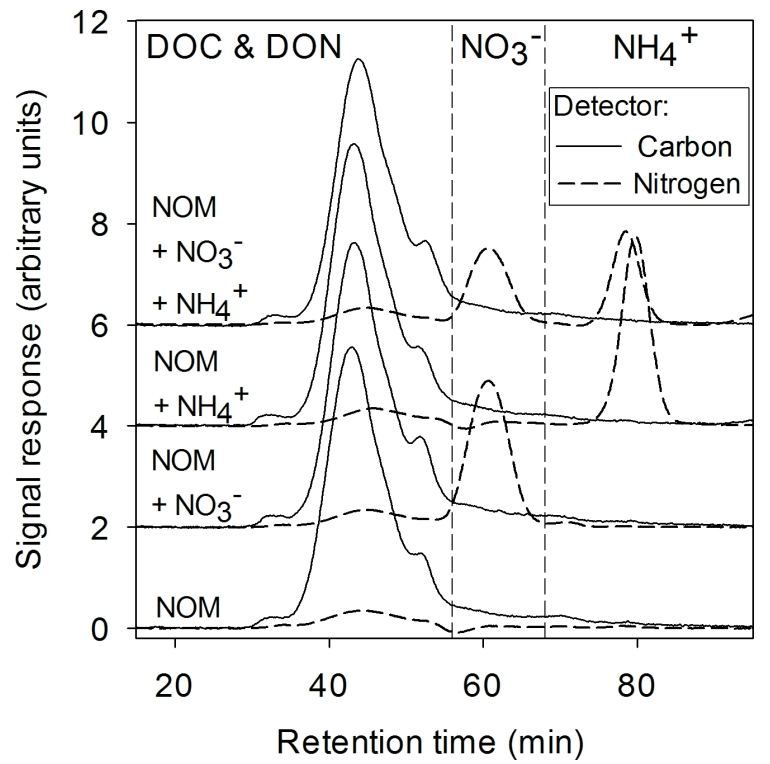

Fig. 3. Size-exclusion chromatograms of Fuchskuhle natural organic matter (NOM) with added $\mathrm{NO}_{3}^{-}$and/or $\mathrm{NH}_{4}^{+}$. Please see Table 1 for further details on the samples.

covery rates were 83,95 and $95 \%$ for the addition with $\mathrm{NO}_{3}^{-}$, $\mathrm{NH}_{4}^{+}$and $\mathrm{NH}_{4}^{+}+\mathrm{NO}_{3}^{-}$, respectively.

The DON concentrations determined by the standard approach were often deviating from that measured by SEC and were even negative for some samples with DIN : TDN ratios $\geq 0.8$ (Table 4). For forest stream 1 and forest stream 2, this was not the case as the standard approach and SEC gave similar results (Table 4). Moreover, the CVs indicate that DON was measured with higher certainty by SEC than by the standard approach for the agricultural streams and tile drain, as well as waste water 2 (Table 4). 
Table 4. DON concentrations of natural samples determined by the standard approach as HTCO-TDN minus DIN or directly by SEC as SEC-DON. Please see Table 1 for further details on the samples. Mean concentrations $\left(\mathrm{mg} \mathrm{N} \mathrm{L}^{-1}\right)$, standard deviations and coefficients of variation $(\mathrm{CV})$ are given. CVs are given as percentages $(\mathrm{CV}=$ standard deviation $\cdot 100 /$ mean $) .{ }^{*}$ indicates significant differences between the results of the two measurement methods according to the bootstrap test (see Appendix A for details on the test). DIN : TDN ratio was calculated as DIN : TDN ratio $=\left(\left(\mathrm{NO}_{3}^{-}+\mathrm{NO}_{2}^{-}\right)+\mathrm{NH}_{4}^{+}\right) /\left(\mathrm{SEC}-\mathrm{DON}+\left(\mathrm{NO}_{3}^{-}+\mathrm{NO}_{2}^{-}\right)+\mathrm{NH}_{4}^{+}\right)$.

\begin{tabular}{lrrrr}
\hline & & HTCO-TDN minus DIN & \multicolumn{2}{c}{ SEC-DON } \\
\cline { 3 - 4 } Sample & & \multicolumn{2}{c}{ Mean conc. \pm 1 SD $(\mathrm{CV})$} & DIN : TDN \\
\cline { 3 - 4 } Forest stream 1 & & $0.05 \pm 0.02(40)$ & $0.07 \pm 0.01(18)$ & 0.59 \\
Forest stream 2 & $*$ & $0.07 \pm 0.01(18)$ & $0.08 \pm 0.01(7)$ & 0.60 \\
Waste water 1 & $*$ & $-2.23 \pm 0.22(10)$ & $0.78 \pm 0.14(19)$ & 0.94 \\
Waste water 2 & $*$ & $-2.88 \pm 0.29(10)$ & $1.06 \pm 0.09(8)$ & 0.94 \\
GER agric. stream & & $-0.94 \pm 0.35(37)$ & $0.84 \pm 0.12(14)$ & 0.89 \\
GER agric. tile drain & & $0.10 \pm 0.19(189)$ & $0.27 \pm 0.05(20)$ & 0.99 \\
DK agric. stream 1 & $*$ & $-0.20 \pm 0.05(24)$ & $0.17 \pm 0.01(4)$ & 0.94 \\
DK agric. stream 2 & $*$ & $-0.18 \pm 0.06(34)$ & $0.33 \pm 0.01(3)$ & 0.91 \\
\hline
\end{tabular}

\section{Discussion}

\subsection{Errors of the standard approach}

The measurement error of DON was strongly influenced by the DIN:TDN ratio if DON was calculated as $\mathrm{DON}=\mathrm{TDN}-\left(\mathrm{NO}_{3}^{-}+\mathrm{NO}_{2}^{-}\right)-\mathrm{NH}_{4}^{+}$in the standard approach. Frequently, high errors even led to negative determined DON concentrations, yielding DIN : TDN ratios higher than 1 (Fig. 1). The error of the DON determination increased with higher DIN : TDN ratios due to the fact that similarly high absolute errors in $\mathrm{NO}_{3}^{-}+\mathrm{NO}_{2}^{-}, \mathrm{NH}_{4}^{+}$and TDN measurements are larger relative to the DON concentration at higher DIN : TDN ratios. We showed that large errors of the determined DON concentrations are a common problem in the measurement of stream water samples at high DIN : TDN ratios $>0.6-0.8$ (Figs. 1 and 2).

According to our data, the HTCO-TDN measurement is the main source of error in DON concentrations determined by the standard approach. Similar relationships between the DIN : TDN ratio and the DON measurement error were found in another study using HTCO (Lee and Westerhoff, 2005), and also for persulfate digestion (Vandenbruwane et al., 2007). Moreover, Lee and Westerhoff (2005) showed that at DIN : TDN ratios of $0.8-0.9$, DON concentrations of the samples were over- or underestimated by a factor of 0.5 to 2 (figure 4 in Lee and Westerhoff (2005)). This is in accordance with our results, as we found false estimations by factors ranging between 0.25 and 2.1 for a DIN : TDN ratio of 0.8 (Fig. 4). In one case (wetland outflow $+\mathrm{NO}_{3}^{-}$), we even determined a negative DON concentration $\left(-0.32 \mathrm{mg} \mathrm{N} \mathrm{L}^{-1}\right.$ ) by the standard approach. Hence, the problem of high DON random measurement errors seems to be a common problem caused by many types of TDN measurements, since even small random errors of TDN measurements propagate into large DON random errors at high DIN : TDN ratios. Ac- cording to our data, an accurate TDN measurement would strongly improve the accuracy of the DON determination by the standard approach. However, different TDN measurement techniques (Thermo Flash, different HTCO models, persulfate digestion) have not yet been systematically compared regarding their ability to accurately determine DON concentrations in relation to varying DIN : TDN ratios for standard compounds and natural substances.

At low concentrations $\left(\approx 0.5 \mathrm{mg} \mathrm{N} \mathrm{L}^{-1}\right)$, we consistently found an overestimation of HTCO-TDN measurements for standard compounds and natural samples. We could not determine the reason for this and even a calibration curve for low concentrations did not improve the recovery rates for the standard compounds. This overestimation at low TDN concentrations may also have been the reason for the pronounced overestimations of the Fuchskuhle NOM with added DIN (Fig. 4). The Fuchskuhle NOM with added $\mathrm{NO}_{3}^{-}$and $\mathrm{NH}_{4}^{+}$ was measured diluted, with HTCO-TDN concentrations of $0.70-0.76 \mathrm{mg} \mathrm{N} \mathrm{L}^{-1}$ for the diluted sample. At similarly low concentrations $\left(0.5 \mathrm{~m} \mathrm{~N} \mathrm{~L}^{-1}\right)$, the HTCO-TDN measurement also resulted in overestimations of the TDN concentrations for the standard compounds (Table 2). No such problems have been found in previous publications on HTCOTDN measurements (Bronk et al., 2000), which makes an unknown systematic measurement error of the HTCO measurements at low TDN concentrations likely for our study. However, the strong influence of variability in the HTCOTDN measurements on the random errors of the determined DON concentrations at high DIN : TDN ratios remains valid without this additional systematic error.

Already at a DIN : TDN ratio $>0.6$, larger errors occurred for the determined DON concentration, a finding which is in accordance with another study (Lee and Westerhoff, 2005). The large errors of the DON concentration at high DIN : TDN ratios found in our study appear to be a common problem that occurs in the measurement of samples 
from several freshwater systems (Lee and Westerhoff, 2005; Siemens and Kaupenjohann, 2002; Solinger et al., 2001; Vandenbruwane et al., 2007). This suggests that future studies in freshwaters should apply measures to increase DON measurement accuracy at high DIN : TDN ratios.

\subsection{Comparison of standard approach and size-exclusion chromatography}

Our study shows that size-exclusion chromatography (SEC) results in high DON recovery rates similar to those of TDN by HTCO (Table 2). High SEC recovery rates have also been recorded by Huber et al. (2011b) for standard compounds, even for EDTA which is considered difficult to oxidize and hence to measure (Bronk et al., 2000). Moreover, SEC resulted in high recovery rates of DON, irrespective of the DIN : TDN ratio for both standard compounds and reverseextracted NOM (Fig. 4; Fuchskuhle NOM and Schwarzer See NOM) and a natural sample with DIN addition (wetland outflow). These high recovery rates are a result of the clear separation of DON from DIN peaks by the chromatographic column of the SEC (Fig. 3, see Supplement for the other chromatograms). The only samples for which DON and DIN were not perfectly separated were the samples from the waste water treatment plant outflows, for which the imperfect separation may have lead to a slight underestimation of DON (see supplement for chromatograms). However, for these samples no DON was detected according to the standard approach and the well detectable DON concentration ( 0.78 and $\left.1.06 \mathrm{mg} \mathrm{N} \mathrm{L}^{-1}\right)$ of the SEC measurement underpins the usefulness of the direct DON determination (Table 4). The SEC also detected DON concentrations of 0.17$0.84 \mathrm{mg} \mathrm{N} \mathrm{L}^{-1}$ for the agricultural streams, which should not contain DON according to the standard approach (Table 4).

In the absence of DIN, DON of Schwarzer See NOM was underestimated by $19 \%$ by SEC in comparison to the HTCOTDN measurement. This may be the result of not fully oxidized nitrogen compounds occurring in the UV reactor of the SEC. However, after addition of DIN and at a DIN : TDN ratio of 0.8 , the standard approach often yielded poorer recovery rates than the SEC measurement (Fig. 4).

Altogether, we successfully tested SEC on samples from waste water treatment plant outflows, a wetland outflow, NOM from a lake and a pond, forest and agricultural streams (Fig. 4, Table 4). Thus, for DON samples from surface freshwaters, SEC represents a significant methodological advance and can thus be recommended for DON measurement of samples with high DIN:TDN ratios (>0.6). In addition, SEC not only separates DON from DIN but also allows separation of different DON fractions (Huber et al., 2011b).

With the phosphate buffer used for the SEC measurements in our study, urea elutes together with $\mathrm{NO}_{3}^{-}$and $\mathrm{NH}_{4}^{+}$and may thus be falsely attributed to DIN. However, for the analysis of urea, the same system setting can be applied except for a phosphate buffer, which is five times weaker in ionic

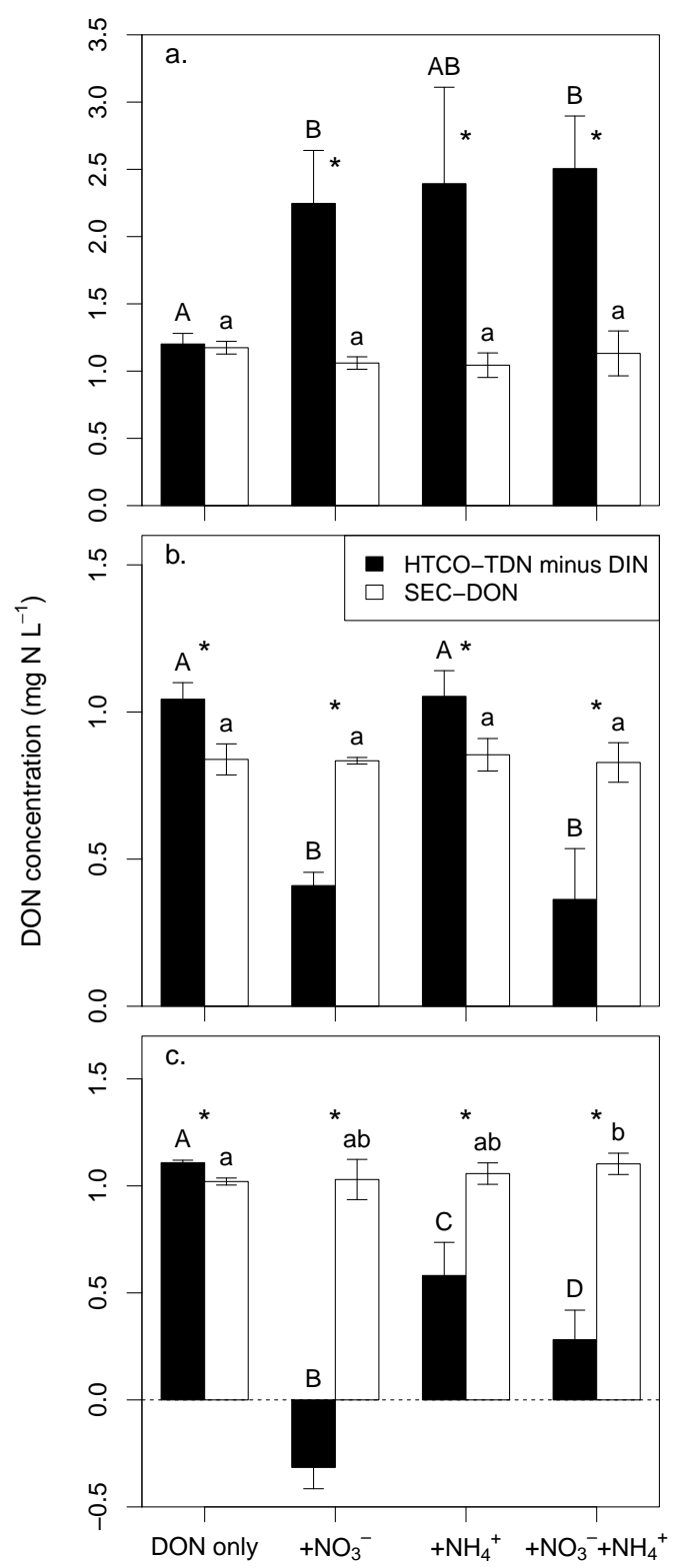

Fig. 4. Mean $( \pm 1 \mathrm{SD})$ of $D O N$ calculated by the standard approach $\left(\mathrm{HTCO}-\mathrm{TDN}\right.$ minus DIN $\left(\mathrm{DIN}=\left(\mathrm{NO}_{3}^{-}+\mathrm{NO}_{2}^{-}\right)+\mathrm{NH}_{4}^{+}\right), 6$ 11 measurement replicates) or measured by size-exclusion chromatography (SEC-DON, 5 measurement replicates) for different natural organic matter treatments (NOM). (a) Fuchskuhle NOM, (b) Schwarzer See NOM, (c) Wetland outflow. $\mathrm{NO}_{3}^{-}$and/or $\mathrm{NH}_{4}^{+}$ was added to the samples so that a DIN : TDN ratio of 0.8 was reached. The treatment without added $\mathrm{NO}_{3}^{-}$and/or $\mathrm{NH}_{4}^{+}$is indicated as "DON only", the treatments with additions are indicated as " $+\mathrm{NO}_{3}^{-}$", " $+\mathrm{NH}_{4}^{+}$" or " $+\mathrm{NO}_{3}^{-}+\mathrm{NH}_{4}^{+}$". Means and uncertainties of the standard approach were calculated by MC simulations. Letters indicate significant differences between the treatments: capital letters for the standard-approach determinations and small letters for the SEC-DON measurements. Asterisks indicate significant differences between the results from the standard-approach and SECDON determinations (pairwise bootstrap test). Please see Table 1 for further details on the samples. 
strength. This alternative setting yields a clearly resolved urea peak and allows quantitative detection of urea concentrations (Huber et al., 2011a). However, the high-molecular DON is less well resolved with this alternative setting (Huber et al., 2011a). In freshwaters in which urea is likely to occur, this alternative setting should thus be employed.

During SEC-DON measurements, a part of the DON may theoretically remain in the SEC column and is therefore not measured by the nitrogen detector (Huber et al., 2011b). In our study, no detectable influence of this potential measurement error was found, as no consistent underestimations occurred in SEC-DON concentrations for standard compounds or NOM. Moreover, for the tested standard compounds, recovery rates of SEC-DON were similar or even closer to $100 \%$ than those of the HTCO-TDN measurements, implying that DON remaining in the SEC column did not induce an increase in the error of the SEC-DON measurement.

The time of measurement for SEC-DON is higher $(2.5 \mathrm{~h}$ per sample) than for the single measurements of the standard approach. However, for the standard approach three measurements (TDN, $\mathrm{NO}_{3}^{-}+\mathrm{NO}_{2}^{-}, \mathrm{NH}_{4}^{+}$) need to be conducted to determine the DON concentration for one sample. This, combined with the maintenance and calibration of the instruments, adds up to an amount of time which is roughly comparable to that of one SEC-DON measurement. Moreover, the SEC system used in our study was equipped with an autosampler allowing measurement of nine samples in $24 \mathrm{~h}$.

The price of the SEC system used in our study is higher than that of standard TDN and DIN measurement equipment. This high price results mainly from the simultaneous oxidation of organic carbon and nitrogen, as well as the simultaneous detection of carbon, nitrogen and $\mathrm{UV}_{254}$ with in-line detectors (Huber et al., 2011b). To reduce the costs of such a system for the direct DON measurement, a simpler system could be set up comprising an auto-sampler, an auto-collector, an HPLC pump and a column. After column passage, water containing only DON could be collected and measured with a TDN analyzer, such as HTCO. An alternative to SEC may be the application of dialysis pretreatment, which is less expensive than SEC and has been thoroughly tested in previous studies (Lee and Westerhoff, 2005; Vandenbruwane et al., 2007). Dialysis pretreatment is, however, more time consuming than SEC and can result in DON loss from the sample (Lee and Westerhoff, 2005; Vandenbruwane et al., 2007).

\section{Conclusions}

The standard approach gave large errors for various surface freshwater samples with high DIN : TDN ratios $(>0.6)$. Therefore, we discourage use of the standard approach, if high DIN : TDN ratios are expected and that methods, such as SEC, are employed in future studies of freshwater systems with high DIN : TDN ratios in order to increase DON mea- surement accuracy. Moreover, we recommend that literature values of DON concentrations determined by the standard approach at high DIN : TDN ratios are regarded with caution.

Altogether, we recommend use of SEC for direct DON measurement in surface freshwater samples with high DIN : TDN ratios $(>0.6)$ since it permits high-accuracy direct measurement of DON concentrations, rendering DON determination independent of the concentration of DIN in the sample and is thus a save method when no previous information on $\mathrm{N}$ species in samples is available. Although we have tested samples from a wide range of freshwater environments, including forest and agricultural streams, a lake, a pond, waste water treatment plant outflows, as well as a wetland in our study, other environments such as soil, groundwater, and coastal and marine environments have not been tested. Therefore, further studies should focus on testing this novel technique for additional systems. However, based on our results, the scientific community will be able to gather more exact information on DON concentrations in anthropogenically disturbed systems such as freshwaters in agricultural and urban areas.

\section{Appendix A}

\section{Description of two-sided, exact bootstrap pairwise test}

The null hypothesis of the bootstrap pairwise test is that, with the probability $\beta$, the difference between the means of two samples is lower than the difference of two means randomly generated from the combination of the two distributions. In order to test this null hypothesis for a pair of samples with $n$ and $m$ replicates, the following steps are conducted to generate 9999 bootstrap resamples: $n$ values are randomly sampled with replacement from the first sample of the tested pair and $m$ values are randomly sampled with replacement from the second sample of the tested pair. These are then merged into a list of $n+m$ values. From this list, two samples of the sizes $n$ and $m$ are sampled with replacement and the difference between their means is calculated. After generating the 9999 bootstrap resamples, the test statistic is calculated as follows (Efron and Tibshirani, 1993):

$p(\hat{\tau})=\frac{1}{B} \cdot \sum_{j=1}^{B} I\left(\left|\tau_{j}\right|>|\hat{\tau}|\right)$,

where $p(\hat{\tau})$ is the significance level, $B$ is the number of bootstrap samples, $\tau_{j}$ is the difference of the random means calculated for each of the bootstrap resamples and $\hat{\tau}$ is the difference between the mean of the two samples. $I$ is an indicator function, which is 1 if $\tau_{j}>\hat{\tau}$ or 0 , if this is not the case. See "bootstrap_test.zip" in the Supplement for the R script. 


\section{Supplementary material related to this article is available online at: http://www.biogeosciences.net/9/ 4873/2012/bg-9-4873-2012-supplement.zip.}

Acknowledgements. We thank Thomas Rossoll, Sarah Schell, Hans-Jürgen Exner and Antje Lüder for their help in the laboratory at the Leibniz-Institute of Freshwater Ecology and Inland Fisheries. Moreover, we thank Anne Mette Poulsen from the Department of Bioscience, Aarhus University, for her assistance with the correction of the English language. This research was funded by the PRESTO-Catch (German Federal Ministry of Education and Research, 01SFF0710), ECOGLOBE (Danish Council for Independent Research (DFF), Natural Sciences, 09-067335), and DONCOPRA (German Science Foundation (DFG), PU 136/7-1 and Foundation for Research Support of the Federal State of Minas Gerais (FAPEMIG), CRA-80/10) project.

Edited by: K. Küsel

\section{References}

Berman, T. and Bronk, D.: Dissolved organic nitrogen: a dynamic participant in aquatic ecosystems, Aquat. Microb. Ecol., 31, 279305, 2003.

Bronk, D., Lomas, M., Glibert, P., Schukert, K., and Sanderson, M.: Total dissolved nitrogen analysis: comparisons between the persulfate, UV and high temperature oxidation methods, Mar. Chem., 69, 163-178, 2000.

Crumpton, W., Isenhart, T., and Mitchell, P.: Nitrate and organic $\mathrm{N}$ analyses with second-derivative spectroscopy, Limnol. Oceanogr., 37, 907-913, 1992.

Efron, B. and Tibshirani, R.: An Introduction to the Bootstrap, Chapman \& Hall, CRC, Boca Raton, UK, 1993.

Huber, S. and Frimmel, F.: Flow-injection analysis of organic and inorganic carbon in the low-ppb range, Anal. Chem., 63, 21222130, 1991.

Huber, S., Balz, A., and Abert, M.: New method for urea analysis in surface and tap waters with LC-OCD-OND (liquid chromatography-organic carbon detection-organic nitrogen detection), J. Water Supply Res. T., 60, 159-166, 2011 a.

Huber, S., Balz, A., Abert, M., and Pronk, W.: Characterisation of aquatic humic and non-humic matter with size-exclusion chromatography-organic carbon detection-organic nitrogen detection (LC-OCD-OND), Water Res., 45, 879-885, 2011 b.
Jørgensen, N.: Organic nitrogen, in: Encyclopedia of Inland Waters, edited by: Likens, G., Elsevier, Amsterdam, Netherlands, 832 851, 2009.

Lee, W. and Westerhoff, P.: Dissolved organic nitrogen measurement using dialysis pretreatment, Environ. Sci. Technol., 39, 879-884, 2005.

Pouillot, R. and Delignette-Muller, M. L.: Evaluating variability and uncertainty separately in microbial quantitative risk assessment using two R packages, Int. J. Food Microbiol., 142, 330-340, 2010.

Quinn, G. and Keough, M.: Experimental Design and Data Analysis for Biologists, vol. 1, Cambridge University Press, Cambridge, UK, 2002.

R Development Core Team: R: A language and environment for statistical computing, available at: http://www.R-project.org (last access: 4 April 2012), 2012.

Rutkoviene, V., Grazuliaviciene, V., Cesoniene, L., and Kusta, A.: Determination of nitrate concentration in natural waters, Russ. J. Appl. Chem., 78, 1864-1868, 2005.

Schlueter, A.: Nitrate interference in total Kjeldahl nitrogen determinations and its removal by anion exchange resins, technical report, Environmental Monitoring Support Laboratory, Cincinnati, USA, 1977.

Siemens, J. and Kaupenjohann, M.: Contribution of dissolved organic nitrogen to $\mathrm{N}$ leaching from four German agricultural soils, J. Plant Nutr. Soil Sc., 165, 675-681, 2002.

Solinger, S., Kalbitz, K., and Matzner, E.: Controls on the dynamics of dissolved organic carbon and nitrogen in a Central European deciduous forest, Biogeochemistry, 55, 327-349, 2001.

van Kessel, C., Clough, T., and van Groenigen, J.: Dissolved organic nitrogen: an overlooked pathway of nitrogen loss from agricultural systems?, J. Environ. Qual., 38, 393-401, 2009.

Vandenbruwane, J., De Neve, S., Qualls, R., Salomez, J., and Hofman, G.: Optimization of dissolved organic nitrogen (DON) measurements in aqueous samples with high inorganic nitrogen concentrations, Sci. Total Environ., 386, 103-113, 2007.

Verdouw, H., van Echteld, C., and Dekkers, E.: Ammonia determination based on indophenol formation with sodium salicylate, Water Res., 12, 399-402, 1978.

Worsfold, P., Monbet, P., Tappin, A., Fitzsimons, M., Stiles, D., and McKelvie, I.: Characterisation and quantification of organic phosphorus and organic nitrogen components in aquatic systems: a review, Anal. Chim. Acta, 624, 37-58, 2008. 